\title{
Erratum to: Simulation of Electron Trajectories in the Multicusp Ion Source Using Geant4 Monte Carlo Code
}

Fatemeh Khodadadi Azadboni • Mahmood Sedaghatizade

Published online: 25 December 2009

(C) Springer Science+Business Media, LLC 2009

\section{Erratum to: J Fusion Energ}

DOI 10.1007/s10894-009-9248-4

Unfortunately the title of article had been erroneously published as Simulation of Electron Trajectories in the Multicusp Ion Source Using Geantn4 Monte Carlo Code and has to be as Simulation of Electron Trajectories in the Multicusp Ion Source Using Geant4 Monte Carlo Code

The online version of the original article can be found under doi:10.1007/s10894-009-9248-4.

F. Khodadadi Azadboni · M. Sedaghatizade

Department of Physics, K.N. Toosi University of Technology,

41, Shahid Kavian St., 15875-4416 Tehran, Iran

F. Khodadadi Azadboni ( $\square)$

Member of Young Researchers Club, Islamic Azad University,

Sari Branch, 48161-194 Sari, Iran

e-mail: fatemeh@sina.kntu.ac.ir;

fatemeh.khodadadiazadboni8@gmail.com 